\title{
Factors Influencing the Adoption of E-Health Management among Saudi Citizens with Moderating Role of E-Health Literacy
}

\author{
Waleed Mansi G Alshammari ${ }^{1}$, Fahad Maiyah M Alshammari² \& Faiz Mayah M Alshammry ${ }^{3}$ \\ ${ }^{1,3}$ King Khalid Hospital, Ha'il, Saudi Arabia \\ ${ }^{2}$ Universiti Teknologi Malaysia (UTM), Malaysia \\ awaleedmansi2021@gmail.com, maiyah@graduate.utm.my, faizmayahmalshammry2021@gmail.com
}

\begin{abstract}
This study aimed to examine the role of internet access, social influence, facility access, and cost concerns on E-health adoption in Saudi Arabia with moderating role of E-health literacy. Saudi citizens were the targeted population of this study. To fulfill the objectives of this study, quantitative research methods with a cross-sectional technique were applied. A self-administrative survey was employed with a questionnaire to collect the data. This study used the purposive sampling method for the collection. Structure equation modeling was applied by using Smart PLS 3 to analyze the data. The findings of the current study show that internet access, social influence, and facility access have significant and positive effects on E-health adoption. Cost concerns have a significant and negative influence on the Adoption of E-Health Management services. Results revealed that E-health literacy has a significant and positive moderating role in the association of internet access, facility access, and cost concerns on E-health adoption. Results of this study contribute to the body of literature by finding that internet access, social influence, facility access, and cost concerns have a significant effect on the Adoption of E-Health Management services and E-health literacy is essential to improve the Adoption of E-Health Management services.
\end{abstract}

Keywords: E-health adoption, E-health literacy, internet access, social influence, facilities access, cost concerns.

\section{Introduction and Background of the Study}

Electronic health has become a new concept of service delivery in healthcare by consolidating technology, commerce, and health (Pagliari et al., 2005). Telemedicine is an applied example of E-health that is categorized into three aspects likely health in our hands, permitting data for health, and making healthassociated interactions (Basheer, Raoof, Jabeen, \& Hassan, 2021; Greenhalgh et al., 2017). E-health platforms are useful for the monitoring of individuals' health or in a blended care environment. A blended platform in the E-health care environment refers to the online collaboration among individual patients and professionals associated with healthcare services (van Zelst et al., 2021). Similarly, remote vital signs monitoring enabled the full potential of E-health platforms with the support of increasing demand for moveable monitoring equipment generally in the last ten years and particularly after the eruption of the COVID-19 pandemic (Basheer, Siam, Awn, \& Hassan, 2019). Now, consumer healthcare behavior is changing from a reactive hospital-centered approach towards a proactive individual-centered approach that focuses on the early discovery and cure of illnesses with personalized health services (Zhao, Yang, \& Wong, 2018). After the outbreak of CVID-19, the scope of telemedicine has increased remarkably. With the recognition of telemedicine among the patients as well as service providers, E-health platforms are grown widely.

However, studies that address the association of medical practitioners' attitudes and the perceived utility of E-health platforms are very few. Over time, E-health market platforms are becoming more competitive that enabling developers of E-health platforms to review and add more important components for making them more profitable to medical service providers. In this study, researchers intend to explore the impact of Ehealth platform features in the relation of attitude towards E-health platforms and the perceived E-Health platforms utility. In addition, E-Health is associated with the software application that incorporates process, methods, and information delivery mechanisms in assisting e-healthcare practices. Moreover, it helps in the management and communication of information in a healthcare system that ultimately provides better performance of healthcare professionals while making practice and improved health of a patient. Accordingly, Varshney, Allahloh, and Sarfraz (2019) described E-Health as the adoption and implementation of "Information and Communication Technology (ICT)" while performing various activities included in the healthcare system. The range of these activities incorporates all of the information such as information regarding the hospital, workers, billing, payment information, and historical record of the patient in the contemporary context. 
It also includes internet usage to store, transform, and apply information associated with health. In extension, the E-Health concept has a much wider scope that includes the digitalization of numerous activities and methods of healthcare from primary to advanced services level that introduces new terms of e-appointments, e-records, e-delivery, e-billing, and e-payments. Although, there are numerous implications of ICT in the sector of healthcare, however, this study only focuses on the basic e-Health facilities offered by the clinics such as e-appointment, and e-payments, and e-billing because they are easy and feasible for patients to use. With the help of these basic services, communication among patients and health care service providers become time-saving and easy. In this study, researchers integrate ECM with the Technology Acceptance Model (TAM) for the identification of essential factors. Based on this tradition, this study focus on the integration of security and privacy perceived as an important element of post-adoption behavior to comprehend the e-Health facilities (Wong, 2018). In the literature, previous studies included PPS as background in the study of post-adoption consumer behavior while adopting different e-services that include e-banking and e-management.

In addition, this research also incorporates perceived trust which exceptionally influences E-health adoption. For this reason, this research anticipates that role of these two additional variables will be significantly important while predicting the post-adoption behavior of e-Health. In the literature, evidence found that health education positively influences healthy lifestyle behavior (Sumaedi \& Sumardjo, 2020). For this purpose, the internet is one of the communication channels that provide health education. Internet usage carries various advantages for public health education activities extensively (Aziz, Zulkifli, \& Rahardjo, 2016; Sumaedi \& Sumardjo, 2020; Sumaedi, Sumardjo, Saleh, \& Syukri, 2021; Yuan, Ma, Kanthawala, \& Peng, 2015). Previously, many researchers found that there is a research gap regarding internet usage for health purposes. Following this, Alhuwail and Abdulsalam (2019) evaluated the purpose behind attaining health information from the internet and the extent of social media use in searching information regarding health in the context of Kuwait. They conclude that the most common reason for getting health information from the internet is that it is perceived to be more informed and interested. However, the amount of health information explored through social media is limited.

With the population of Taiwanese students, Du, Liu, Cai, Hu, and Dong (2020) studied the association among personal features, E-Health knowledge, and healthy lifestyles where they conclude that personal characteristics and E-Health literacy have a significant influence on a healthy lifestyle. Similarly, Mitsutake, Shibata, Ishii, and Oka (2016) evaluated the same association of E-Health literacy towards healthy lifestyle behavior by taking Japanese adults as the population of the study. They conclude that E-Health literacy significantly affects healthy lifestyle behavior. Moreover, Ashraf (2020) evaluated the elements that influence E-Health literacy and the use of web 2.0. In their study, they found that E-Health literacy perceives influence from age, qualification, and number of internet equipment. Web 2.0 uses for health purposes are affected by gender, qualification, and the number of internet devices used to access it. In their study, Kim, Yoo, Hwang, and Cho (2019) evaluated the components that have an impact on the attitude of consumers using Internet health portal and their behavioral purposes for using "health information technology (HIT)". Meanwhile, they empirically establish that attitude of users and behavioral intentions are importantly influenced by the anticipated hazard, practicality, and friendly use.

In addition, they concluded that health position, health concerns, and beliefs, personal values, HIT elements, and HIT self-efficacies indirectly influence the attitude and behavioral intentions of users. According to the literature, numerous factors affect the use of the internet for health purposes. Primarily, internet search behavior that indicates the health literacy of an individual influences internet usage for health purposes. Additionally, other studies found that the use of the internet for health is subjective to factors including social inspirations (M. Al-Azzam \& Alazzam, 2019; Khasawneh, Nusair, Arabyat, Karasneh, \& Al-Azzam, 2021), access to internet facilities (Al-Azzam \& Alazzam, 2019; Khan, Xitong, Ahmad, \& Shahzad, 2019) and personal enthusiasm (Yuan et al., 2015). Besides this, numerous researchers concluded significant influence of perceived health information on the internet regarding the use of the internet for health (Boland, Juntunen, Kim, Adams, \& Navarro, 2019; Dahleez, Bader, \& Aboramadan, 2020; Yu et al., 2021). Moreover, the perceived threat of ailment also significantly impacts internet usage with the purpose of health (Ahadzadeh, Sharif, Ong, \& Khong, 2015; Koivumäki et al., 2017; Mattila, Koivumäki, Caldwell, \& Semini, 2017). In the literature, researchers conducted studies regarding internet usage for health purposes but still. 
Some research gaps prevail first, no research model exists that at the same time evaluate the influence of internet access behavior, social inspiration, access of internet facility, and cost considerations for purposes of health. Next, hedonic consumption theory states that motivation includes two kinds of motivations i.e. hedonic and utilitarian motivation (Hirschman \& Holbrook, 1982). While using the internet by someone, both kinds of motivations may be there. In addition, both of these kinds of motivations may have dissimilar effects on the use of the internet. However, no research in the literature evaluates the influence of motivation considering utilitarian and hedonic motivation distinctively. Then, the social influence model explains that social influence encompasses two kinds of norms i.e. descriptive and injunctive norms (Bossuyt, Pouillon, Bonnaud, Danese, \& Peyrin-Biroulet, 2017). In the prevailing studies regarding the use of the internet for health meanings, research is dominated by the injunctive norms of social influence. In contrast, descriptive kind of norm may have a more significant influence on the use of the internet for health reasons (Yan, Basheer, Irfan, \& Rana, 2020; Yuan et al., 2015). Still, this research gap is not comprehensively addressed by the researchers. By considering this research gap, researchers in this study intended to evaluate the influence of internet searching behavior, social influence, and access of internet facilities, and cost concerns on E-health adoption in the Saudi Arabian context with the moderating effect of E-health literacy.

\section{Literature Review}

Adoption of E-Health Management: With the rapid and increasing use of internet-based ICT in various areas, it has become an important topic of research (Ahadzadeh et al., 2015; Alhuwail \& Abdulsalam, 2019; Leung \& Chen, 2019). Social interventions are also guided by the use of the internet to change behavior regarding a healthy lifestyle (Lee, Le, Lal, Engel, \& Mihalopoulos, 2021; Yu et al., 2021). Internet usage is described by the researchers as actions of individuals while using the internet for certain activities including accessing or sharing content (Alhuwail \& Abdulsalam, 2019; Bol, Helberger, \& Weert, 2018; Klinger et al., 2015; Vázquez et al., 2018). Accordingly, the use of the internet for health purposes can be described as activities of individuals while using the internet for certain actions that facilitate his or her health including searching or communicating contents associated with health. Furthermore, behavior elements contain cognitive, emotional, conative, and spiritual elements. Aziz et al. (2016) differentiate these actions from the other three elements of behavior evaluation. Research of Sumaedi and Sumardjo (2020) is followed by this study because that there can be a difference among the influencing actions as compared to the factors that influence other components of behavior.

Use of internet in various fields is studied by the numerous researchers (Alhuwail \& Abdulsalam, 2019; Bol et al., 2018; Korkmaz Aslan, Kartal, Turan, Taşdemir Yiğitoğlu, \& Kocakabak, 2021; Lee et al., 2021). In general, the use of the internet is measured by the frequency of internet usage for particular activities (Alhuwail \& Abdulsalam, 2019; Bol et al., 2018; Dashti, Peyman, Tajfard, \& Esmaeeli, 2017; Hoque \& Bao, 2015). Hence, more often a person searches for his activities on the internet, the level of internet usage increases. Concerning the consumption of the internet for health reasons, the use of the internet is also measured by the rate of internet usage. Mostly, researchers measure the level of internet usage for health purposes by considering the searching rate of the internet (Bol et al., 2018; Van Deen et al., 2016). In addition, some researchers use the measurement of internet usage by considering the searching frequency of the internet as well as other activities on the internet (Mattila et al., 2017) divides into three classes namely health caring, material searching regarding health, and sharing its information. For this study, the second method is opted because of two reasons. Firstly, the advancement of ICT has made internet channels appropriate for obtaining health data and other associated events (Asada, Basheerb, Irfanc, Jiangd, \& Tahir, 2020; Zimmerman \& Shaw Jr, 2020).

Domínguez-Mayo et al. (2015) stated that E-Health includes e-health care, e-health material, e-health business, e-health communication, and e-health platform. Secondly, multiple social media platforms are there that enable users to collaborate and communicate information regarding health (Tennant et al., 2015). Alternatively, this method allows users to use the internet for more than one purpose at the same time. By considering this, this research measures the use of the internet for health reasons by considering the searching regularity of health information, use of health sessions, and sharing of information regarding health on the internet. By integrating findings of previous studies regarding the use of the internet with the theories namely "Theory of Planned Behavior" (TPB) (Ajzen, 2020), "Health Belief of Model" (HBM) (Abraham \& 
Sheeran, 2015), "Hedonic Consumption Theory" (Saeed, Yang, \& Sinnappan, 2009), and "Unified Theory of Acceptance and Use of Technology" (UTAUT)(Venkatesh, Thong, \& Xu, 2012), researchers proposed in this research that use of the internet for health purposes is influenced by the many factors. These factors consist of internet access behavior that includes purpose, approaches and information, cost concerns, factors of social influence that include injunctive and descriptive norms, access to the facility, factors of motivation including hedonic and utilitarian motivation and perceived e-information regarding health.

\section{Hypotheses Development}

Internet Access Behavior: The digital divide phenomenon is among the topics that are commonly discussed (Van Deursen \& Van Dijk, 2019). This phenomenon represents a difference in internet access among individuals. Internet access is defined by the researchers as a state that facilitates users to utilize the internet (Van Deursen \& Helsper, 2015b). In general, researchers are agreed upon the two kinds of internet access are access linked with the internet facilities and access linked with the behavior of individuals(van Laar, van Deursen, van Dijk, \& de Haan, 2019). Rahardjo, Lubis, and Harijati (2016) state that access linked with the behavior of individuals is termed as Internet access behavior. Moreover, Mulyadi, Rahardjo, and Basuki (2016) described that Internet access behavior consists of cognitive, conative, and affective components. Alternatively, it includes knowledge, attitude, and intention of an individual behind internet use. This is in line with the studies of Van Deursen and Van Dijk (2019) and van Laar et al. (2019).

Here, knowledge refers to the vision possessed by an individual regarding the use of the internet (Rahardjo et al., 2016). Furthermore, attitude is concerned with the spirits of an individual concerning the internet and its use (Ajzen, 2020; Rahardjo et al., 2016; Raoof, Basheer, Shabbir, Ghulam Hassan, \& Jabeen, 2021). Furthermore, the intention is concerned with the tendency of using the internet by someone (Maringer et al., 2018). For the two reasons, this research considers internet access behavior as knowledge, attitude, and intention of an individual. Firstly, it is proved in the literature that these three components are concerned with the use of the internet (Sumaedi \& Sumardjo, 2020). Secondly, behavior associated with health that is shaped by the knowledge, attitude, and intention have a greater tendency of sustainability (Petty, Briñol, \& Tormala, 2002). Based on the above discussion, hypotheses are formed as under:

Hypothesis 1: Internet access behavior has a significant influence on the Adoption of E-Health Management.

Social Influence: Social influence (SI) is concerned with the perception of patients that how their associates believe about E-health adoption (Venkatesh et al., 2012). The idea behind the SI is that the behavior of an individual is motivated by the perception of how others will recognize him/her after using services of Ehealth. Accordingly, friends, families, and groups in society may influence the decision of a user towards Ehealth (Nkosi \& Mekuria, 2010; Quaosar, Hoque, \& Bao, 2018). In the opinion of Al-Khowaiter, Dwivedi, and Williams (2015), SI is pertinent to the E-health services because of the reason that interaction towards Ehealth is potentially evaluated by others in social life and that influential groups shape the intention of technology adoption (Nadri, Rahimi, Afshar, Samadbeik, \& Garavand, 2018). Studies on the information systems concluded a significant association of SI and adoption of E-Services (Nadri et al., 2018; Y. Sun, Wang, Guo, \& Peng, 2013). Illustratively, Sun and Tang (2011) determined that SI shapes the behavioral intention of using services regarding E-health.

Ciranka and van den Bos (2021) further found that there is an association between the relation of SI and behavioral intention of users of health care digital information applications. While studying this relation, there are two groups of scholars with two different points of view. First, social influence is guidance given from those people that are admitted significant for someone while taking some decision (Al-Azzam, Alazzam, \& Al-Manasra, 2019; Duarte \& Pinho, 2019; Khatri et al., 2015). Moreover, this group of researchers considers as the injective norm of social influence while shaping behavior. According to the second stream, social influence is comprised of descriptive and injunctive norms (Pedersen, Grønhøj, \& Thøgersen, 2015; Sharps \& Robinson, 2017). As compared to the injunctive norm, descriptive norm describes the degree of importance for those who are considered significant by the person who is performing behavior particularly (KoenigLewis, Marquet, Palmer, \& Zhao, 2015; Sharps \& Robinson, 2017). In this way, the injunctive norm is associated with the endorsements of important people while practicing a behavior by someone. 
However, the descriptive norm is concerned with the practices made by those people who are related to behavior (Sun \& Tang, 2011; van Zelst et al., 2021). Generally, studies associated with ICT and internet usage use injunctive norms in the evaluation of social influence (Al-Azzam \& Alazzam, 2019; Murray \& Schaller, 2016; Yu et al., 2021). In contrast, some researchers highlighted that only injunctive norms are not enough for the social influence representation and they added descriptive norms too for the purpose (Bautista Jr, Jeong, \& Pandey, 2020; Lazuras \& Dokou, 2016). Social influence measured by using only injunctive norm may cause an insignificant effect of social influence on ICT (Yuan et al., 2015). Hence, this study incorporates both injective as well as subjective norms to evaluate social influence. The use of the internet can be subjective to the social influence according to UTAUT (Khatimah, Susanto, \& Abdullah, 2019). Moreover, some of the researchers determined that usage of E-Health services is impacted by social influence (Al-Azzam \& Alazzam, 2019). Based on the above discussion, the hypothesis is formed as under:

Hypothesis 2: Social influence has a significant influence on the Adoption of E-Health Management.

Facility Access: In the literature, internet facility access and physical internet access are the terms that are often used in the same meanings (Pitchford et al., 2017). For the first time, this concept was recognized as the cause of internet usage level differences. From the perspective of theory, this concept is the substitute of facilitating conditions concept prevailed in UTAUT. UTAUT states that the easiness of using the internet results in more internet use (Venkatesh et al., 2012). By defining internet access facility, it is the state of resources having an individual that facilitates the use of the internet (Van Deursen \& Helsper, 2015a; Van Deursen \& Van Dijk, 2019). These resources made easy access to the internet for users (Cajita, Hodgson, Lam, Yoo, \& Han, 2018). More comprehensively, internet access facility comprises internet network availability, infrastructure to support this network, equipment of ICT, and required finance to meet these needs (Van Deursen \& Van Dijk, 2019). Concerning this research, internet facility access contains ICT equipment availability required for usage of internet, finance required for internet usage, Wi-Fi networks, and electricity availability. According to UTAUT, the use of the internet is influenced by the internet access facility (Venkatesh et al., 2012). More specifically, some studies found that the use of e-networks for health purposes is associated positively with access to facilities (Duarte \& Pinho, 2019).

Facility access is the extent of a patient's perception that a physical or technical organization prevails to facilitate E-Health usage. Bhattacherjee, Davis, Connolly, and Hikmet (2018) determined that support of infrastructure significantly play role in the usage of e-facilities. Further, it was concluded that facility access positively improves the behavioral intentions of clients for using smartphones to avail E-Health facilities (Boontarig, Chutimaskul, Chongsuphajaisiddhi, \& Papasratorn, 2012; Rahimi, Nadri, Afshar, \& Timpka, 2018). However, users are required to possess aptitude, information, and means essentially required for E-Health usage. Appropriate E-Health services usage is dependent on the accessibility of infrastructure and networks of organizations needed for better results. So, the degree of patient's perception regarding infrastructure and network in the effective use of E-Health services may decide the use of e-services. In response to the lack of means and technical support, some of the users are reluctant to adopt these services. For this reason, it is expected that perceived resources facilitation has a positive impact on the intention of using E-Health. Based on the above discussion, the hypothesis is formed as under:

Hypothesis 3: Facility access has a significant influence on the Adoption of E-Health Management.

Cost Concerns: Cost concerns (CCs) are associated with the perceived degree of expenses that a patient recognizes while opting for E-Health likewise cost of equipment Ahuja and Khazanchi (2016) and its financial burdens. Behavioral decision theory Gong (2015) states that the cost-benefit ratio significantly impacts technology adoption. Meanwhile, if users of E-Health services presume that benefits from E-Health are more than its cost of investment, they will show a positive behavior towards E-health usage. Yarbrough and Smith (2007) have the opinion that cost elements are widely overlooked in the previous studies on the topic. Besides, Aydin, Özer, and Arasil (2005) paid to focus on the importance of switching costs on the loyalty of customers in their national indices of customer satisfaction. Although the Adoption of E-Health Management services results in better service delivery and increase clinical efficiency, the perceived cost of E-health technology is very high. In the overall E-health cost, not only devices cost include but it also includes development, configuration, transferring, and maintenance expenses (Hosseini, Fatemifar, \& Rahimzadeh, 2015). Moreover, learning costs may also be included in it because learning about the newly introduced services is required (Burnham, Frels, \& Mahajan, 2003). 
However, bad experiences of clients regarding slow speed, bad quality, pause, and missing links may lead users to dissatisfaction. Accordingly, the cost may be the deciding factor for customers for accepting E-health services. If the cost of a new E-health app is high in the perception of a patient, he/she will avoid its use. Consequently, the high cost of E-health value-added services negatively influences the intention of the customer in choosing that particular technology. Cheong and Park (2005) also conducted a study in the Korean context by incorporating the perceived cost element to examine the intention of using E-health services. According to some researchers, the cost associated with accessing, devices, and transactions charge importantly shapes the perception of users, and negative perception influences adoption of services negatively (Cheong \& Park, 2005; Chong, Chan, \& Ooi, 2012). Some of the studies in the literature also concluded that cost is a more significant element of deciding intention regarding the use of the internet as compared to privacy apprehensions (Lin, Lu, \& Hsieh, 2011). Based on the above discussion, the hypothesis is formed as under:

Hypothesis 4: Cost concerns have a significant influence on the Adoption of E-Health Management.

E-Health Literacy: The E-health literacy (E-HL) concept is described as the capability of searching, exploring, understanding, and evaluating information regarding health by using electronic channels and implementing this acquired knowledge to resolve a health problem (Coşkun \& Bebiş, 2015). Users of smartphones commonly search for health information or issues on their devices. Pew Research Centre conducted a survey and concluded that $62 \%$ of users of smart devices in the US search about health topics (Briones, 2015). Recent studies in the context of Saudi Arabia concluded that an increasing trend of internet and social media use for health information search (Alsahafi, Gay, \& Khwaji, 2020; Mehmood, Ghani, Chen, \& Alghamdi, 2019). For appropriate use of e-health services, essential e-HL abilities are needed that enable users to search and comprehend health information (Walsh et al., 2017). The transformation from a hospital-centric approach to a consumer-centric approach guides governments to stimulate healthcare provision cost reduction and inspire consumers to resolve health issues proactively (Koumakis et al., 2017; Vamos et al., 2019). This transformation also highlights the significance of healthcare education and training to the users (Alsahafi et al., 2020; Walsh et al., 2017). Therefore, e-HL is now becoming an important area of consideration for public health in response to the advancing HIT that enabled healthcare users with easy availability of healthassociated knowledge by using various media channels (Mackert, Mabry-Flynn, Champlin, Donovan, \& Pounders, 2016). Electronic information sources are increasing rapidly that enable users to search, recognize.

Obtain and implement concerning health information effectively with consumer-centric technologies specifically (Magsamen-Conrad, Dillon, Billotte Verhoff, \& Faulkner, 2019). The main purpose behind the implementation of the national integrated system is to provide individuals more access to their health histories and to motivate them for participating more effectively in their health management $(\mathrm{H}$. Kim \& Xie, 2017). Several studies found a significant association of e-HL with health technologies usage. Among the elements that create hurdles in the adoption of My Health Record, e-HL is also one of them in the Australian context (Walsh et al., 2017). Hence, the E-HL level influences the perception level of healthcare users regarding the effectiveness of E-Health services. People with a higher level of e-HL were found to be more positive about the Adoption of E-Health Management technologies because they consider it highly beneficial and ultimately help them in improving their overall health (Magsamen-Conrad et al., 2019). Based on the above discussion, the hypothesis is formed as under:

Hypothesis 5: E-health literacy has a significant moderating role in the relationship between internet access and Adoption of E-Health Management.

Hypothesis 6: E-health literacy has a significant moderating role in the relationship of social influence and Adoption of E-Health Management.

Hypothesis 7: E-health literacy has a significant moderating role in the relationship of facility access and Adoption of E-Health Management.

Hypothesis 8: E-health literacy has a significant moderating role in the relationship of cost concerns and the Adoption of E-Health Management.

\section{Methodology}

Data was collected by applying a survey questionnaire from the target population for analysis purposes. The Saudi residents were the population of the current study who used E-health applications for health purposes. 
The current study examined the role of internet access, social influence, facility access, and cost concerns on E-health adoption in Saudi Arabia with moderating role of E-health literacy. The population of the current study is unknown because there is no database of those Saudi citizens who have used E-health applications. Therefore, this study employed purposive sampling for the collection of data. The quantitative research approach was applied and a survey with purposive sampling was initiated. The purposive sampling is employed because this sampling technique is adequate in these conditions (Ahmad Sabir, Mohammad, \& Kadir Shahar, 2019; Park \& Sullivan, 2009). Moreover, this sampling method is still suitable for the estimation of the literature-based model (M. F. Basheer, Hameed, Sabir, \& Jehangir, 2019; Hameed, Waseem, Sabir, \& Dahri, 2020). Based on the selected sampling technique, a total of 300 questionnaires were distributed, however, only 212 responses were obtained, out of 212 received responses 14 responses were incomplete. Incomplete questionnaires were not included in the analysis. The majority of the respondents were 25- 35 years old with school education. The five-point Likert scale was applied with strongly disagree to strongly agree for the measurement of the variable. For hypotheses testing, structure equation modeling was employed by using Smart-PLS software.

\section{Analysis and Discussion}

Figure: 1 A Two-Step Process of PLS Path Model Assessment. To Analyze the Data and Report of Results, the Two-Step Approach was used in Smart-PLS Statistical Software According to the Recommendations of Henseler, Ringle, and Sinkovics (2009). Below Fig. 1 Shows the Two-Step PLSSEM Process

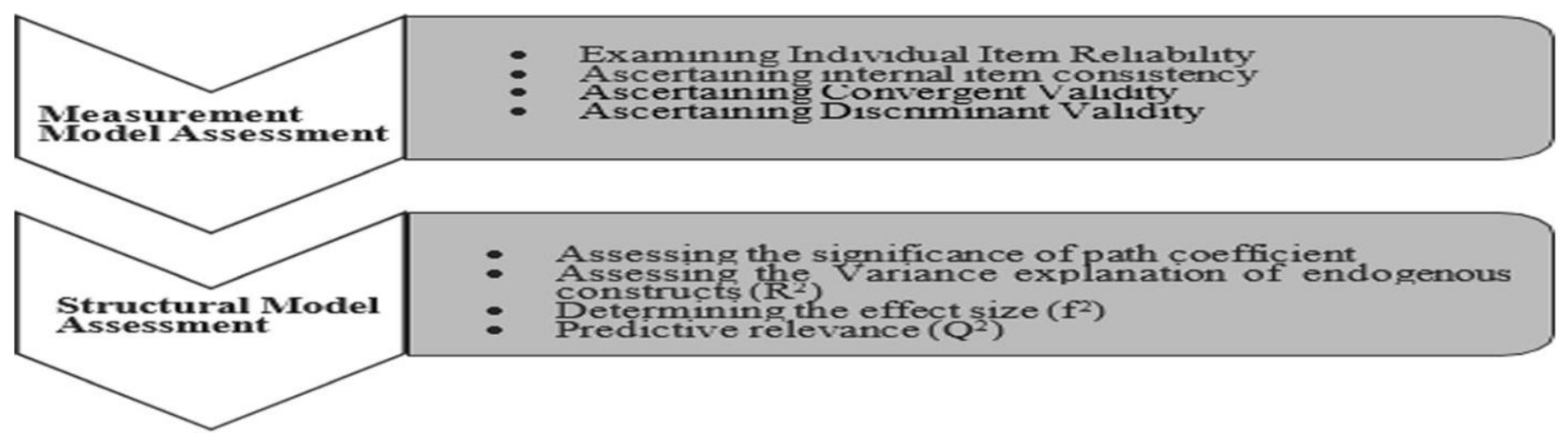

Source: (Henseler et al., 2009).

Measurement Model Assessment: Measurement model analysis was executed to inspect the validity and reliability of constructs. The threshold value of variable reliability is based on Cronbach's alpha coefficient, composite reliability (CR), and average variance extracted (AVE). The reliability of construct is fulfilled if the value of Cronbach's alpha $(\alpha)$ is equal to or above 0.6 and the value of CR and AVE is above or equal to 0.5 (George \& Mallery, 2003). The validity of the construct is measured by the value of the square root of AVE and the value of HTMT ratios (Fornell \& Lacker, 1981). The measurement model's results are given in Figure 2 and Table 1, Table 2, and Table 3. 
Figure 2: Measurement Model Assessment

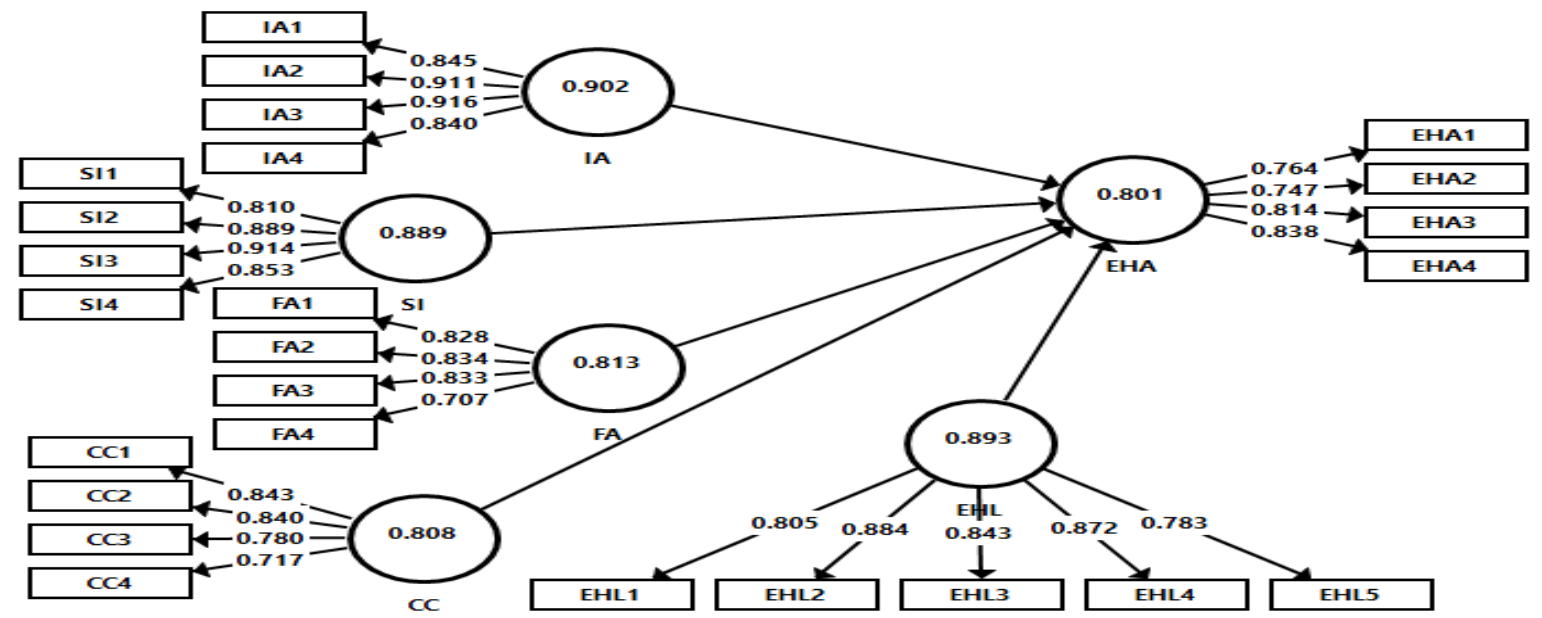

Table 1: Internal Consistency, Convergent Validity, Composite Reliability and AVE

\begin{tabular}{|c|c|c|c|c|c|}
\hline Construct & Indicators & Loadings & Cronbach's alpha & $\begin{array}{l}\text { Composite } \\
\text { Reliability }\end{array}$ & AVE \\
\hline \multirow[t]{4}{*}{ E-Health Adoption } & EHA1 & 0.764 & 0.801 & 0.870 & 0.626 \\
\hline & EHA2 & 0.747 & & & \\
\hline & EHA3 & 0.814 & & & \\
\hline & EHA4 & 0.838 & & & \\
\hline \multirow[t]{4}{*}{ Internet access } & IA1 & 0.845 & 0.902 & 0.931 & 0.772 \\
\hline & IA2 & 0.911 & & & \\
\hline & IA3 & 0.916 & & & \\
\hline & IA4 & 0.840 & & & \\
\hline \multirow[t]{4}{*}{ Social influence } & SI1 & 0.810 & 0.889 & 0.924 & 0.752 \\
\hline & SI2 & 0.889 & & & \\
\hline & SI3 & 0.914 & & & \\
\hline & SI4 & 0.853 & & & \\
\hline \multirow[t]{4}{*}{ Facility access } & FA1 & 0.828 & 0.813 & 0.878 & 0.644 \\
\hline & FA2 & 0.834 & & & \\
\hline & FA3 & 0.833 & & & \\
\hline & FA4 & 0.707 & & & \\
\hline \multirow[t]{4}{*}{ Cost concerns } & CC1 & 0.843 & 0.808 & 0.874 & 0.635 \\
\hline & $\mathrm{CC} 2$ & 0.840 & & & \\
\hline & CC3 & 0.780 & & & \\
\hline & CC4 & 0.717 & & & \\
\hline \multirow[t]{5}{*}{ E-Health literacy } & EHL1 & 0.805 & 0.893 & 0.922 & 0.702 \\
\hline & EHL2 & 0.884 & & & \\
\hline & EHL3 & 0.843 & & & \\
\hline & EHL4 & 0.872 & & & \\
\hline & EHL5 & 0.783 & & & \\
\hline
\end{tabular}

Table 1 indicates that all constructs are established the reliability and validity of the value of Cronbach's alpha $(\alpha)$, CR and AVE are according to the threshold values (Fornell \& Lacker, 1981). 
Table 2: Fornell-Larcker Criterion

\begin{tabular}{lllllll}
\hline & CC & EHA & EHL & FA & IA & SI \\
\hline CC & 0.797 & & & & & \\
EHA & 0.658 & 0.792 & & & & \\
EHL & 0.545 & 0.636 & 0.838 & & & \\
FA & 0.490 & 0.520 & 0.529 & 0.802 & 0.879 & \\
IA & 0.448 & 0.518 & 0.758 & 0.520 & 0.450 & 0.867 \\
SI & 0.336 & 0.403 & 0.466 & 0.582 & 0 \\
\hline
\end{tabular}

Table 2 indicates that this study established discriminant validity according to the recommendations of Fornell and Lacker (1981) because the square root of AVE is greater than the correlation with other variables.

Table 3: Heterotrait-Monotrait Ratio (HTMT)

\begin{tabular}{|c|c|c|c|c|c|c|}
\hline & CC & EHA & EHL & FA & IA & SI \\
\hline CC & & & & & & \\
\hline EHA & 0.798 & & & & & \\
\hline EHL & 0.627 & 0.752 & & & & \\
\hline FA & 0.596 & 0.648 & 0.622 & & & \\
\hline IA & 0.512 & 0.601 & 0.834 & 0.601 & & \\
\hline SI & 0.387 & 0.478 & 0.522 & 0.684 & 0.493 & \\
\hline
\end{tabular}

Table 3 indicated that the values of HTMT are established the discriminant validity of the model because the value of HTMT is less than 0.85 . Therefore, this study achieves the criteria of HTMT to confirm the discriminant validity.

\section{Structural Model Assessment}

Figure 3: Structural Model Assessment

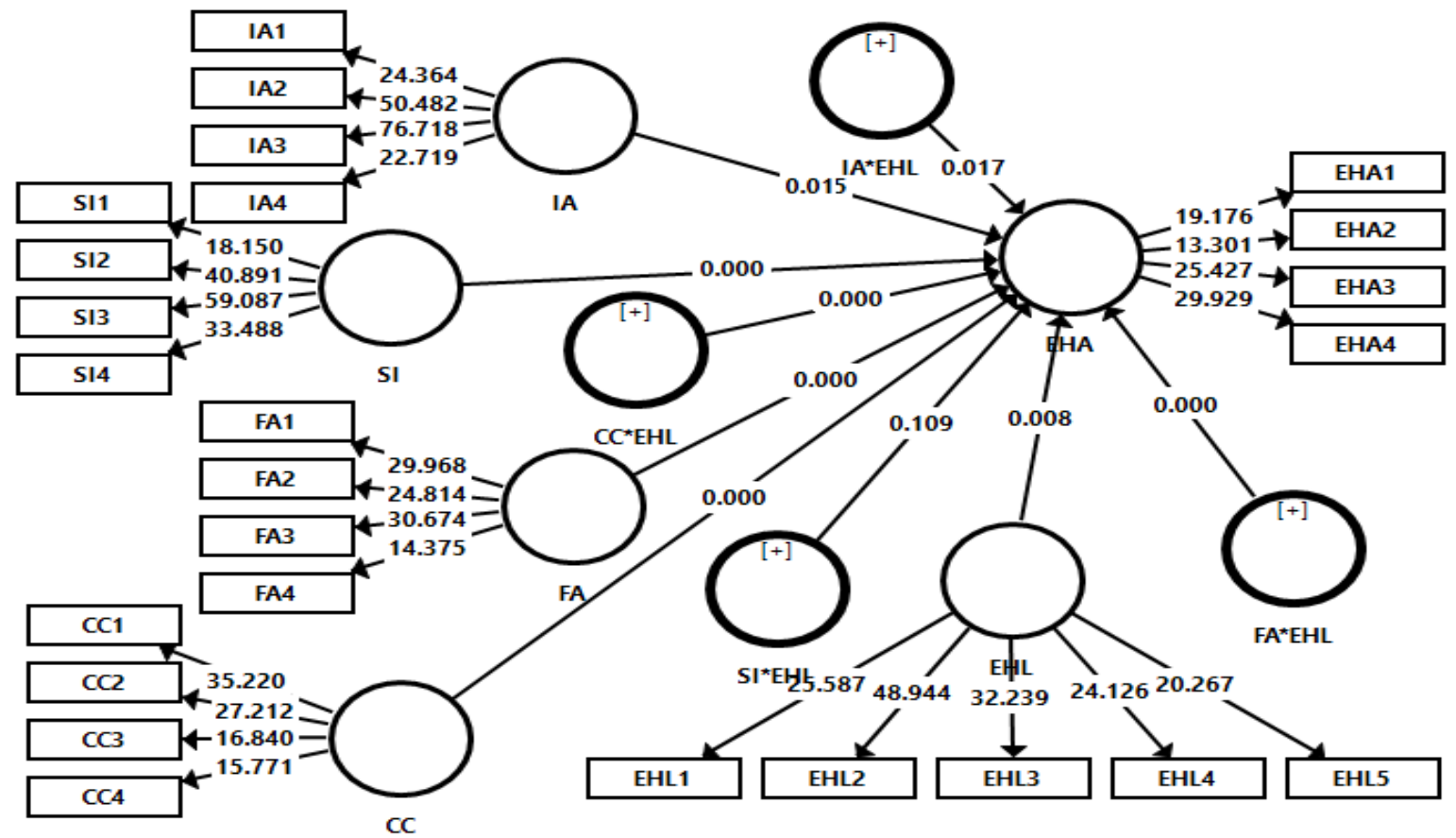


Table 4: Structural Model Assessment (Direct Effect Results and Decision)

\begin{tabular}{llllll}
\hline Hypotheses & Relationship & Beta & STD & T Value & P Values \\
\hline $\mathbf{H}_{\mathbf{1}}$ & IA - > EHA & 0.427 & 0.082 & 2.780 & 0.015 \\
$\mathbf{H}_{\mathbf{2}}$ & SI - EHA & 0.365 & 0.070 & 5.241 & 0.000 \\
$\mathbf{H}_{\mathbf{3}}$ & FA - EHA & 0.243 & 0.090 & 2.681 & 0.000 \\
$\mathbf{H}_{\mathbf{4}}$ & CC - EHA & -0.427 & 0.058 & 7.368 & 0.000 \\
\hline
\end{tabular}

The bootstrapping method in PLS statistical software was employed for the estimation of hypotheses of this study. Results show that internet access has a significant and positive effect on the Adoption of E-Health Management services $(\beta=0.427, t=2.780)$, therefore, $\mathrm{H}_{1}$ is accepted on the statistical ground. Social influence also has a significant effect on the Adoption of E-Health Management services $(\beta=0.365, t=5.241)$, therefore, $\mathbf{H}_{2}$ is accepted. Moreover, facilities access has a significant and positive role in the Adoption of E-Health Management services $(\beta=0.243, t=2.681)$, thus, $H_{3}$ is accepted. Furthermore, cost concern has a significant but negative effect on the Adoption of E-Health Management services $(\beta=-0.427, t=7.368)$, hence, $\mathrm{H}_{4}$ is accepted.

Table 5: Structural Model Assessment (Moderation Effects)

\begin{tabular}{llllll}
\hline Hypotheses & Relationship & Beta & STD & T Value & P Values \\
\hline $\mathbf{H}_{\mathbf{5}}$ & IA*EHL - EHA & 0.348 & 0.092 & 0.348 & 0.017 \\
$\mathbf{H}_{\mathbf{6}}$ & SI*EHL - EHA & -0.101 & 0.063 & 1.605 & 0.109 \\
$\mathbf{H}_{7}$ & FA*EHL - EHA & 0.262 & 0.080 & 3.281 & 0.000 \\
$\mathbf{H}_{\mathbf{8}}$ & CC*EHL - > EHA & 0.310 & 0.068 & 4.568 & 0.000 \\
\hline
\end{tabular}

Table 5 indicates the moderation role of E-health literacy on the relationship of internet access, social influence, facility access, and cost concerns on E-health adoption. Results indicated that E-health literacy has a significant moderation effect on the relationship of internet access with the Adoption of E-Health Management services $(\beta=0.348, t=0.348)$. Hence, $\mathrm{H}_{5}$ is accepted. Moreover, $\mathrm{E}$-health literacy significantly moderates the relationship of facilities access with the Adoption of E-Health Management services $(\beta=0.262$, $\mathrm{t}=3.281$ ). Therefore, $\mathrm{H}_{6}$ is supported. Furthermore, E-health literacy has a significant moderating effect on the relationship of cost concerns with the Adoption of E-Health Management services $(\beta=0.310, t=4.568)$. Thus, $\mathbf{H}_{\mathbf{6}}$ is supported.

\section{Discussion and Conclusion}

This study aimed to examine the effect of internet access, social influence, facility access, and cost concerns on E-health adoption in Saudi Arabia with moderating role of E-health literacy. This study found that internet access significantly affects the Adoption of E-Health Management services. More specifically, internet access behavior positively affects the adoption of electronic health services in Saudi Arabia. This means that the Adoption of E-Health Management services depends on someone's internet access or how frequently he uses internet services. This result was supported by TPB (Ajzen, 1991) and UTAUT (Venkatesh et al., 2012). Furthermore, the findings of the current study show that social influence also has a significant and positive effect on the adoption of electronic health services. This finding is in line with the study of Alaiad, Alsharo, and Alnsour (2019). Facilities access also has a significant and positive effect on the adoption of electronic health services, while cost concerns have a significant but negative effect on the adoption of electronic health services.

These results are consistent with Alaiad et al. (2019). Findings depict that E-health literacy has a significant moderating role in the relationship of internet access, facilities access, and cost concerns with the adoption of electronic health services. This study contributes to the literature on E-health adoption in several ways. Based on the findings of the current study, the government and related organizations need to improve the level of someone's internet access and facilities access to increase the Adoption of E-Health Management services. Moreover, E-health plays an important role in the Adoption of E-Health Management services. Therefore, the government should focus to enhance the knowledge of someone concerning E-health (Paige et al., 2018). 
Based on the limitations, future studies are needed to be conducted in other contexts to observe the constancy of our study findings. Second, future research is needed by incorporating other factors that may affect the Adoption of E-Health Management services.

\section{References}

Abraham, C. \& Sheeran, P. (2015). The health belief model. Predicting health behavior: Research and practice with social cognition models, 2, 30-55.

Ahadzadeh, A. S., Sharif, S. P., Ong, F. S. \& Khong, K. W. (2015). Integrating health belief model and technology acceptance model: an investigation of health-related internet use. Journal of medical Internet research, 17(2), e3564.

Ahmad Sabir, S., Mohammad, H. \& Kadir Shahar, H. (2019). The role of overconfidence and past investment experience in herding behavior with a moderating effect of financial literacy: evidence from Pakistan stock exchange. Asian Economic and Financial Review, 9(4), 480-490.

Ahuja, V. \& Khazanchi, D. (2016). Creation of a conceptual model for adoption of mobile apps for shopping from e-commerce sites-An Indian context. Procedia Computer Science, 91, 609-616.

Ajzen, I. (1991). The theory of planned behavior. Organizational behavior and human decision processes, $50(2), 179-211$.

Ajzen, I. (2020). The theory of planned behavior: Frequently asked questions. Human Behavior and Emerging Technologies, 2(4), 314-324.

Al-Azzam, M. \& Alazzam, M. B. (2019). Smart city and smart-health framework, challenges and opportunities. Int. J. Adv. Comput. Sci. Appl, 10(2), 171-176.

Al-Azzam, M. K., Alazzam, M. B. \& Al-Manasra, M. K. (2019). MHealth for decision-making support: A case study of EHealth in the public sector. International Journal of Advanced Computer Science and Applications, 10(5), 381-387.

Al-Khowaiter, W. A., Dwivedi, Y. K. \& Williams, M. D. (2015). Examining the role of social influence, usefulness and ease of use for determining the mandatory use of a human resource information system in the context of Saudi Ministries. International Journal of Electronic Government Research (IJEGR), 11(3), 24-42.

Alaiad, A., Alsharo, M. \& Alnsour, Y. (2019). The determinants of m-health adoption in developing countries: An empirical investigation. Applied clinical informatics, 10(05), 820-840.

Alhuwail, D. \& Abdulsalam, Y. (2019). Assessing electronic health literacy in the state of Kuwait: Survey of internet users from an Arab state. Journal of medical Internet research, 21(5), e11174.

Alsahafi, Y. A., Gay, V. \& Khwaji, A. A. (2020). Factors affecting the acceptance of integrated electronic personal health records in Saudi Arabia: The impact of e-health literacy. Health Information Management Journal, 1833358320964899.

Asada, A., Basheerb, M. F., Irfanc, M., Jiangd, J. \& Tahir, R. (2020). Open-Innovation and Knowledge Management in Small and Medium-Sized Enterprises (SMEs): The role of External Knowledge and Internal Innovation. Revista Argentina de Clínica Psicológica, 29(4), 80-90.

Ashraf, B. N. (2020). Stock markets' reaction to COVID-19: Cases or fatalities? Research in International Business and Finance, 54, 101249.

Aydin, S., Özer, G. \& Arasil, Ö. (2005). Customer loyalty and the effect of switching costs as a moderator variable: A case in the Turkish mobile phone market. Marketing intelligence \& planning.

Aziz, R., Zulkifli, F. Y. \& Rahardjo, E. T. (2016). Dual-arm modified-spiral textile antenna for wearable medical communication applications. Paper presented at the 2016 International Conference on Electromagnetics in Advanced Applications (ICEAA).

Basheer, M., Siam, M., Awn, A. \& Hassan, S. (2019). Exploring the role of TQM and supply chain practices for firm supply performance in the presence of information technology capabilities and supply chain technology adoption: A case of textile firms in Pakistan. Uncertain Supply Chain Management, 7(2), 275-288.

Basheer, M. F., Hameed, W. U., Sabir, S. A. \& Jehangir, M. S. (2019). Islamic Business Ethics and Islamic Banks Performance in Malaysia: Does Sincerity Matter? Hamdard Islamicus, 42(4), 225-241.

Basheer, M. F., Raoof, R., Jabeen, S. \& Hassan, S. G. (2021). Exploring the Nexus Among the Business Coping Strategy: Entrepreneurial Orientation and Crisis Readiness-A Post-COVID-19 Analysis of Pakistani 
SMEs Handbook of Research on Entrepreneurship, Innovation, Sustainability, and ICTs in the PostCOVID-19 Era (pp. 317-340): IGI Global.

Bautista Jr, R., Jeong, L. S. \& Pandey, S. (2020). Will Cause-Related Marketing Affect the American and Filipino College Students' Purchase Intention? Asia-Pacific Social Science Review, 20(4).

Bhattacherjee, A., Davis, C. J., Connolly, A. J. \& Hikmet, N. (2018). User response to mandatory IT use: A coping theory perspective. European Journal of Information Systems, 27(4), 395-414.

Bol, N., Helberger, N. \& Weert, J. C. (2018). Differences in mobile health app use: a source of new digital inequalities? The Information Society, 34(3), 183-193.

Boland, D. H., Juntunen, C. L., Kim, H. Y., Adams, E. M. \& Navarro, R. L. (2019). Integrated behavioral health curriculum in counseling psychology training programs. The Counseling Psychologist, 47(7), 10121036.

Boontarig, W., Chutimaskul, W., Chongsuphajaisiddhi, V. \& Papasratorn, B. (2012). Factors influencing the Thai elderly intention to use smartphone for e-Health services. Paper presented at the 2012 IEEE symposium on humanities, science and engineering research.

Bossuyt, P., Pouillon, L., Bonnaud, G., Danese, S. \& Peyrin-Biroulet, L. (2017). E-health in inflammatory bowel diseases: more challenges than opportunities? Digestive and Liver Disease, 49(12), 1320-1326.

Briones, R. (2015). Harnessing the web: how e-Health and e-Health literacy impact young adults' perceptions of online health information. Medicine, 2.0, 4(2).

Burnham, T. A., Frels, J. K. \& Mahajan, V. (2003). Consumer switching costs: a typology, antecedents, and consequences. Journal of the Academy of Marketing Science, 31(2), 109-126.

Cajita, M. I., Hodgson, N. A., Lam, K. W., Yoo, S. \& Han, H. R. (2018). Facilitators of and barriers to mHealth adoption in older adults with heart failure. Computers, informatics, nursing: CIN, 36(8), 376.

Cheong, J. H. \& Park, M. C. (2005). Mobile internet acceptance in Korea. Internet research.

Chong, A. Y. L., Chan, F. T. \& Ooi, K. B. (2012). Predicting consumer decisions to adopt mobile commerce: Cross country empirical examination between China and Malaysia. Decision support systems, 53(1), 34-43.

Ciranka, S. \& van den Bos, W. (2021). Adolescent risk-taking in the context of exploration and social influence. Developmental Review, 61, 100979.

Coşkun, S. \& Bebiş, H. (2015). Psychometric evaluation of a Turkısh version of the e-health literacy scale (eheals) in adolescents. Gülhane Tip Dergisi, 57(4), 378.

Dahleez, K. A., Bader, I. \& Aboramadan, M. (2020). E-health system characteristics, medical performance and healthcare quality at UNRWA-Palestine health centers. Journal of Enterprise Information Management.

Dashti, S., Peyman, N., Tajfard, M. \& Esmaeeli, H. (2017). E-Health literacy of medical and health sciences university students in Mashhad, Iran in 2016: a pilot study. Electronic physician, 9(3), 3966.

Domínguez-Mayo, F. J., Escalona, M., Mejías, M., Aragón, G., García-García, J. A., Torres, J. \& Enríquez, J. (2015). A strategic study about quality characteristics in e-health systems based on a systematic literature review. The Scientific World Journal, 2015.

Du, S., Liu, W., Cai, S., Hu, Y. \& Dong, J. (2020). The efficacy of e-health in the self-management of chronic low back pain: A meta-analysis. International journal of nursing studies, 106, 103507.

Duarte, P. \& Pinho, J. C. (2019). A mixed-methods UTAUT2-based approach to assess mobile health adoption. Journal of Business Research, 102, 140-150.

Fornell, C. \& Lacker, D. (1981). Two structural equation models with unobservable variables and measurement error. 18.

George, D. \& Mallery, P. (2003). Reliability analysis. SPSS for Windows, step by step: a simple guide and reference, 14th Ed. Boston: Allyn \& Bacon, 222-232.

Gong, S. (2015). The Mobile Technology Acceptance Mechanism of Ningbo Electronic Commerce Enterprise under Government Intervention. Paper presented at the International Conference on Materials Engineering and Information Technology Applications (MEITA 2015).

Greenhalgh, T., Wherton, J., Papoutsi, C., Lynch, J., Hughes, G., Hinder, S. \& Shaw, S. (2017). Beyond adoption: a new framework for theorizing and evaluating non-adoption, abandonment, and challenges to the scale-up, spread, and sustainability of health and care technologies. Journal of medical Internet research, 19(11), e367.

Hameed, W. U., Waseem, M., Sabir, S. A. \& Dahri, A. S. (2020). Effect of enterprise risk management system and implementation problem on financial performance: An empirical evidence from Malaysian listed firms. Abasyn Journal of Social Sciences, 12. 
Henseler, J., Ringle, C. M. \& Sinkovics, R. R. (2009). The use of partial least squares path modeling in international marketing New challenges to international marketing: Emerald Group Publishing Limited.

Hirschman, E. C. \& Holbrook, M. B. (1982). Hedonic consumption: emerging concepts, methods and propositions. Journal of Marketing, 46(3), 92-101.

Hoque, M. R. \& Bao, Y. (2015). Cultural influence on adoption and use of e-Health: evidence in Bangladesh. Telemedicine and e-Health, 21(10), 845-851.

Hosseini, M. H., Fatemifar, A. \& Rahimzadeh, M. (2015). Effective factors of the adoption of mobile banking services by customers. Kuwait Chapter of the Arabian Journal of Business and Management Review, $4(6), 1$.

Khan, I., Xitong, G., Ahmad, Z. \& Shahzad, F. (2019). Investigating factors impelling the adoption of e-health: a perspective of African expats in China. SAGE Open, 9(3), 2158244019865803.

Khasawneh, R. A., Nusair, M. B., Arabyat, R. M., Karasneh, R. \& Al-Azzam, S. (2021). The Association Between eHealth Literacy and Willingness to Deprescribe Among Patients with Chronic Diseases: A CrossSectional Study from Jordan. Telemedicine and e-Health.

Khatimah, H., Susanto, P. \& Abdullah, N. L. (2019). Hedonic motivation and social influence on behavioral intention of e-money: The role of payment habit as a mediator. International Journal of Entrepreneurship, 23(1), 1-9.

Khatri, C., Chapman, S. J., Glasbey, J., Kelly, M., Nepogodiev, D., Bhangu, A. \& Committee, S. (2015). Social media and internet-driven study recruitment: evaluating a new model for promoting collaborator engagement and participation. PloS one, 10(3), e0118899.

Kim, H. \& Xie, B. (2017). Health literacy in the eHealth era: A systematic review of the literature. Patient education and counseling, 100(6), 1073-1082.

Kim, M. N., Yoo, Y. S., Hwang, K. H. \& Cho, O. H. (2019). The effects of office workers' attitudes to internet health information, e-health literacy on health information-seeking behavior and health-related behavioral intention. Journal of Digital Convergence, 17(11), 357-367.

Klinger, E. V., Carlini, S. V., Gonzalez, I., Hubert, S. S., Linder, J. A., Rigotti, N. A. \& Haas, J. S. (2015). Accuracy of race, ethnicity, and language preference in an electronic health record. Journal of general internal medicine, 30(6), 719-723.

Koenig-Lewis, N., Marquet, M., Palmer, A. \& Zhao, A. L. (2015). Enjoyment and social influence: predicting mobile payment adoption. The Service Industries Journal, 35(10), 537-554.

Koivumäki, T., Pekkarinen, S., Lappi, M., Väisänen, J., Juntunen, J. \& Pikkarainen, M. (2017). Consumer adoption of future MyData-based preventive eHealth services: an acceptance model and survey study. Journal of medical Internet research, 19(12), e429.

Korkmaz Aslan, G., Kartal, A., Turan, T., Taşdemir Yiğitoğlu, G. \& Kocakabak, C. (2021). Association of electronic health literacy with health-promoting behaviors in adolescents. International Journal of Nursing Practice, 27(2), e12921.

Koumakis, L., Kondylakis, H., Katehakis, D., Iatraki, G., Argyropaidas, P., Hatzimina, M. \& Marias, K. (2017). A content-aware analytics framework for open health data. Paper presented at the International Conference on Biomedical and Health Informatics.

Lazuras, L. \& Dokou, A. (2016). Mental health professionals' acceptance of online counseling. Technology in Society, 44, 10-14.

Lee, Y. Y., Le, L. K. D., Lal, A., Engel, L. \& Mihalopoulos, C. (2021). The cost-effectiveness of delivering an ehealth intervention, MoodGYM, to prevent anxiety disorders among Australian adolescents: A modelbased economic evaluation. Mental Health \& Prevention, 24, 200210.

Leung, L. \& Chen, C. (2019). E-health/m-health adoption and lifestyle improvements: Exploring the roles of technology readiness, the expectation-confirmation model, and health-related information activities. Telecommunications Policy, 43(6), 563-575.

Lin, F.-R., Lu, I. Y. \& Hsieh, P. S. (2011). Understanding the adoption of wireless sensor network service in households. Paper presented at the 2011 International Joint Conference on Service Sciences.

Mackert, M., Mabry-Flynn, A., Champlin, S., Donovan, E. E. \& Pounders, K. (2016). Health literacy and health information technology adoption: the potential for a new digital divide. Journal of medical Internet research, 18(10), e264. 
Magsamen-Conrad, K., Dillon, J. M., Billotte Verhoff, C. \& Faulkner, S. L. (2019). Online health-information seeking among older populations: Family influences and the role of the medical professional. Health communication, 34(8), 859-871.

Maringer, M., van't Veer, P., Klepacz, N., Verain, M. C., Normann, A., Ekman, S. \& Geelen, A. (2018). Userdocumented food consumption data from publicly available apps: an analysis of opportunities and challenges for nutrition research. Nutrition Journal, 17(1), 1-13.

Mattila, J., Koivumäki, J., Caldwell, D. G. \& Semini, C. (2017). A survey on control of hydraulic robotic manipulators with projection to future trends. iEeE/ASME Transactions on Mechatronics, 22(2), 669680.

Mehmood, Z., Ghani, A., Chen, G. \& Alghamdi, A. S. (2019). Authentication and secure key management in EHealth services: A robust and efficient protocol using biometrics. IEEE Access, 7, 113385-113397.

Mitsutake, S., Shibata, A., Ishii, K. \& Oka, K. (2016). Associations of eHealth literacy with health behavior among adult internet users. Journal of medical Internet research, 18(7), e192.

Mulyadi, S., Rahardjo, W. \& Basuki, A. H. (2016). The role of parent-child relationship, self-esteem, academic self-efficacy to academic stress. Procedia-Social and Behavioral Sciences, 217, 603-608.

Murray, D. R. \& Schaller, M. (2016). The behavioral immune system: Implications for social cognition, social interaction, and social influence Advances in experimental social psychology, 53, 75-129.

Nadri, H., Rahimi, B., Afshar, H. L., Samadbeik, M. \& Garavand, A. (2018). Factors affecting acceptance of hospital information systems based on extended technology acceptance model: a case study in three paraclinical departments. Applied clinical informatics, 9(02), 238-247.

Nkosi, M. T. \& Mekuria, F. (2010). Cloud computing for enhanced mobile health applications. Paper presented at the 2010 IEEE Second International Conference on Cloud Computing Technology and Science.

Pagliari, C., Sloan, D., Gregor, P., Sullivan, F., Detmer, D., Kahan, J. P. \& MacGillivray, S. (2005). What is eHealth (4): a scoping exercise to map the field. Journal of medical Internet research, 7(1), e391.

Paige, S. R., Stellefson, M., Krieger, J. L., Anderson-Lewis, C., Cheong, J. \& Stopka, C. (2018). Proposing a transactional model of eHealth literacy: concept analysis. Journal of medical Internet research, 20(10), e10175.

Park, H. H. \& Sullivan, P. (2009). Market segmentation with respect to university students' clothing benefits sought: Shopping orientation, clothing attribute evaluation, and brand repatronage. International Journal of Retail \& Distribution Management.

Pedersen, S., Grønhøj, A. \& Thøgersen, J. (2015). Following family or friends. Social norms in adolescent healthy eating. Appetite, 86, 54-60.

Petty, R. E., Briñol, P. \& Tormala, Z. L. (2002). Thought confidence as a determinant of persuasion: the selfvalidation hypothesis. Journal of personality and social psychology, 82(5), 722.

Pitchford, L. C., Alves, L. L., Bartschat, K., Biagi, S. F., Bordage, M. C., Bray, I. \& Chachereau, A. (2017). Lxcat: An open-access, web-based platform for data needed for modeling low-temperature plasmas. Plasma Processes and Polymers, 14(1-2), 1600098.

Quaosar, G. A. A., Hoque, M. R. \& Bao, Y. (2018). Investigating factors affecting elderly's intention to use mhealth services: an empirical study. Telemedicine and e-Health, 24(4), 309-314.

Rahardjo, D., Lubis, D. P. \& HARIJATI, İ. S. (2016). Internet Access and Usage in Improving Students' SelfDirected Learning in Indonesia Open University. Turkish Online Journal of Distance Education, 17(2).

Rahimi, B., Nadri, H., Afshar, H. L. \& Timpka, T. (2018). A systematic review of the technology acceptance model in health informatics. Applied clinical informatics, 9(03), 604-634.

Raoof, R., Basheer, M. F., Shabbir, J., Ghulam Hassan, S. \& Jabeen, S. (2021). Enterprise resource planning, entrepreneurial orientation, and the performance of SMEs in a South Asian economy: The mediating role of organizational excellence. Cogent Business \& Management, 8(1), 1973236.

Saeed, N., Yang, Y. \& Sinnappan, S. (2009). User acceptance of Second Life: An extended TAM with hedonic consumption behaviors.

Sharps, M. \& Robinson, E. (2017). Perceived eating norms and children's eating behavior: An informational social influence account. Appetite, 113, 41-50.

Sumaedi, S. \& Sumardjo, S. (2020). Factors influencing internet usage for health purposes. International Journal of Health Governance.

Sumaedi, S., Sumardjo, S., Saleh, A. \& Syukri, A. F. (2021). A model of digital health communication media uses during the Covid-19 pandemic. Health Education. 
Sun, J. \& Tang, J. (2011). A survey of models and algorithms for social influence analysis Social network data analytics (pp. 177-214): Springer.

Sun, Y., Wang, N., Guo, X. \& Peng, Z. (2013). Understanding the acceptance of mobile health services: a comparison and integration of alternative models. Journal of electronic commerce research, 14(2), 183.

Tennant, B., Stellefson, M., Dodd, V., Chaney, B., Chaney, D., Paige, S. \& Alber, J. (2015). eHealth literacy and Web 2.0 health information seeking behaviors among baby boomers and older adults. Journal of medical Internet research, 17(3), e3992.

Vamos, C. A., Griner, S. B., Kirchharr, C., Green, S. M., DeBate, R., Daley, E. M. \& Christiansen, S. (2019). The development of a theory-based eHealth app prototype to promote oral health during prenatal care visits. Translational behavioral medicine, 9(6), 1100-1111.

Van Deen, W. K., van der Meulen-de, A. E., Parekh, N. K., Kane, E. Z. A., DiNicola, C. A. \& Ha, C. Y. (2016). Development and validation of an inflammatory bowel diseases monitoring index for use with mobile health technologies. Clinical gastroenterology and hepatology, 14(12), 1742-1750. e1747.

Van Deursen, A. J. \& Helsper, E. J. (2015a). A nuanced understanding of Internet use and non-use among the elderly. European journal of communication, 30(2), 171-187.

Van Deursen, A. J. \& Helsper, E. J. (2015b). The third-level digital divide: Who benefits most from being online? Communication and information technologies annual: Emerald Group Publishing Limited.

Van Deursen, A. J. \& Van Dijk, J. A. (2019). The first-level digital divide shifts from inequalities in physical access to inequalities in material access. New media \& society, 21(2), 354-375.

van Laar, E., van Deursen, A. J., van Dijk, J. A. \& de Haan, J. (2019). Determinants of 21st-century digital skills: A large-scale survey among working professionals. Computers in human behavior, 100, 93-104.

van Zelst, C. M., Kasteleyn, M. J., van Noort, E. M., Rutten-van Molken, M. P., Braunstahl, G. J. \& Chavannes, N. H. (2021). The impact of the involvement of a healthcare professional on the usage of an eHealth platform: a retrospective observational COPD study. Respiratory Research, 22(1), 1-8.

Varshney, H., Allahloh, A. S. \& Sarfraz, M. (2019). IoT Based eHealth Management System Using Arduino and Google Cloud Firestore. Paper presented at the 2019 International Conference on Electrical, Electronics and Computer Engineering (UPCON).

Vázquez, A., Jenaro, C., Flores, N., Bagnato, M. J., Pérez, M. C. \& Cruz, M. (2018). E-health interventions for adult and aging population with intellectual disability: a review. Frontiers in psychology, 9, 2323.

Venkatesh, V., Thong, J. Y. \& Xu, X. (2012). Consumer acceptance and use of information technology: extending the unified theory of acceptance and use of technology. Mis Quarterly, 157-178.

Walsh, L., Hemsley, B., Allan, M., Adams, N., Balandin, S., Georgiou, A. \& Hill, S. (2017). The e-health literacy demands of Australia's my health record: a heuristic evaluation of usability. Perspectives in health information management, 14(Fall).

Wong, Y. (2018). The New Chinese e-Health Revolution; Healthcare Bus. Int.: London, UK.

Yan, R., Basheer, M. F., Irfan, M. \& Rana, T. N. (2020). Role of Psychological Factors in Employee Well-being and Employee Performance: An Empirical Evidence from Pakistan. Revista Argentina de Clínica Psicológica, 29(5), 638.

Yarbrough, A. K. \& Smith, T. B. (2007). Technology acceptance among physicians: a new take on TAM. Medical Care Research and Review, 64(6), 650-672.

Yu, K., Tan, L., Lin, L., Cheng, X., Yi, Z. \& Sato, T. (2021). Deep-learning-empowered breast cancer auxiliary diagnosis for $5 \mathrm{~GB}$ remote E-health. IEEE Wireless Communications, 28(3), 54-61.

Yuan, S., Ma, W., Kanthawala, S. \& Peng, W. (2015). Keep using my health apps: Discover users' perception of health and fitness apps with the UTAUT2 model. Telemedicine and e-Health, 21(9), 735-741.

Zhao, X., Yang, B. \& Wong, C. W. (2018). Analyzing trend for US immigrants' e-Health engagement from 2008 to 2013. Health communication.

Zimmerman, M. S. \& Shaw Jr, G. (2020). Health information-seeking behavior: a concept analysis. Health Information \& Libraries Journal, 37(3), 173-191. 